\title{
Efforts to emulate human milk oligosaccharides
}

\author{
Rosa María Espinosa ${ }^{1}$, Martha Taméz ${ }^{1}$ and Pedro Prieto ${ }^{1 *}$ \\ ${ }^{1}$ From the Division of Health Sciences Tecnológico de Monterrey - Campus Ciudad de México Calle del Puente 2221438 Tlalpan \\ México D.F., México
}

Research on human milk oligosaccharides (HMO) began with the characterisation of their chemical structures and is now focused on the elucidation of their biological roles. Previously, biological effects could only be investigated with fractions or structures isolated from breast milk; consequently, clinical observations were limited to comparisons between outcomes from breast-fed infants and their formula-fed counterparts. In some cases, it was inferred that the observed differences were caused by the presence of HMO in breast milk. Presently, analytical techniques allow for the fast analysis of milk samples, thus providing insights on the inherent variability of specimens. In addition, methods for the synthesis of HMO have provided single structures in sufficient quantities to perform clinical studies with oligosaccharide-supplemented formulae. Furthermore, studies have been conducted with non-mammalian oligosaccharides with the purpose of assessing the suitability of these structures to functionally emulate HMO. Taken together, these developments justify summarising current knowledge on HMO to further discussions on efforts to emulate human milk in regard to its oligosaccharide content. The present account summarises published data and intends to provide an historical context and to illustrate the state of the field.

Paediatric Nutrition: Breast Milk: Oligosaccharides: Prebiotics

\section{Introduction}

Human milk oligosaccharides (HMO) vary in structure, size and composition and arise from the sequential addition of monosaccharides, such as L-fucose (Fuc), D-N- Acetylglucosamine, (GlcNAc), D-Galactose (Gal) and N-AcetylNeuraminic Acid (NeuAc) to lactose (Galß1-4Glc). The smallest oligosaccharides are generated either when fucose is added to lactose, thus generating the trisaccharides termed fucosyllactoses (2'FL; Fuc $\alpha 1-2$ Gal $\beta 1-4 \mathrm{Glc}$ and 3FL;Gal $\beta 1$ $4[$ Fuc $\alpha 1-3]$ Glc), or when the acidic monosaccharide NeuAc is added to lactose, generating the sialyllactoses ( $3^{\prime} \mathrm{SL}$; NeuAc $\alpha 1-3$ Gal $\beta 1-4 G l c$ and 6'SL; NeuAc $\alpha 1-6$ Gal $\beta 1-4 G l c)$. The relatively high concentration of lactose in milk obscured until recently the presence of the oligosaccharide fraction, which was initially described with the name "gynolactose" and was later analysed and characterised by Grimmonprez and Montreuil ${ }^{1}$. In the same account these researchers hypothesised that lactose induces the synthesis of oligosaccharides; we now know that milk from other mammals may have high concentrations of lactose but contain a limited repertoire of oligosaccharides ${ }^{2,3,4,5}$. Oligosaccharides in milk from marsupials and monotrems are also different ${ }^{6,7}$. With time, it became apparent that milk possessed structures that were not found elsewhere in free, soluble forms. Researchers then began to isolate and characterise HMO to establish catalogues of possible glycoforms and elucidate metabolic pathways. Examples are two of the first comprehensive and systematic accounts of both analytical methodologies and chemical structures published by Kobata and coworkers ${ }^{8,9}$. During the last two decades, explorations of both structure and function increased in number, depth and scope after the discovery of Lewis and Secretor blood group determinants in $\mathrm{HMO}^{10}$. Later on, structures were identified and characterised by biochemical and physical-chemical methods, in some cases corroborating the existence of molecular species ${ }^{11,12}$. As reagents such as polyclonal antibodies raised against immunogenic neo-glycoconjugates ${ }^{13,14}$, monoclonal antibodies raised against cell surface carbohydrates ${ }^{15}$, and lectins became available, it was discovered that HMO structures can also be found as components of glycolipids and glycoproteins ${ }^{16,17}$. Some of these cell surface oligosaccharides have structural motifs that are only expressed at certain stages of tissue development and occasionally reappear in tissues upon malignant transformation $^{18}$. In fact, the use of a monoclonal antibody raised against pancreatic adenocarcinoma with specificity for an oligosaccharide epitope was proposed as a diagnostic tool for cancer ${ }^{15}$. Interestingly, from the discovery of the oligosaccharide fraction of breast milk to the discovery of antigenic determinants in particular structures, the study of HMO follows the development of the science of glycobiology, while emphasis on the nutritional roles of these carbohydrates has only been the focus of intense research in the last decade or so. Discussions on the roles of HMO in paediatric nutrition may be arbitrarily grouped into four areas of inquiry: 1) HMO as analogues of cell surface oligosaccharides used by pathogens and toxins for attachment to mucosa, thus acting as decoys that inhibit bacterial, viral or toxin attachment; 2) HMO as soluble fibres that could act as prebiotics promoting colonisation with beneficial bacteria, facilitating transit

* Corresponding author: Dr Pedro Antonio Prieto - Dirección General Tecnológico de Monterrey - Campus Ciudad de México Calle del Puente 2221438 Tlalpan México D.F., México Tel +52 (55)5483 1604. Fax +52 (55)5483 1606 email paprieto@itesm.mx 
and preventing or controlling colonisation by pathogenic or putrefactive bacteria; 3) as sources of particular monosaccharides, and 4) HMO as substances that interact with the immune system and modulate its response. All of these areas represent actual or putative biological activities that are supported by varying amounts and quality of evidence. The main obstacle to discerning the biological roles of HMO has been the lack of availability of these structures in sufficient quantities and purity to clinically test hypotheses on their biological functions. Several clinical studies have been conducted to compare the physiology and clinical behaviour of breast-fed versus formula-fed infants and in some cases the results of these studies have been attributed to HMO; however, in these instances it has been impossible to ascribe the observed effects exclusively to oligosaccharides since other breast-milk components may elicit or boost particular responses. In the past decade, methods for the synthesis of HMO have yielded kilogram amounts of specific structures that in turn have been used to supplement infant formulae for clinical trials ${ }^{19}$. In the absence of HMO, several groups used non-human oligosaccharides to supplement formulae while seeking to emulate the physiological effects of human oligosaccharides. Two major classes of oligosaccharides have been assessed in clinical experiments in adults and infants and are now being used to supplement commercially available infant formulae: fructooligosaccharides (FOS) and galactooligosaccharides (GOS). FOS can be produced either by taking advantage of the reverse reaction of fructanases or sucrases ${ }^{20}$ or through the enzymatic hydrolysis of inulin ${ }^{21}$, a polymer of fructose. Chemically, both types of FOS differ and commercial literature cites competitive advantages with each type. In terms of composition, FOS synthesised using glycosidases, frequently lack a reducing end and contain one glucose residue and two or more fructose moieties. These are well characterised, the structures have their own names ${ }^{22}$, and are sometimes termed short chain FOS (scFOS). The molecules generated from inulin have free anomeric carbons and generally contain only fructose. On the other hand galactooligosaccharides (GOS) are mostly produced from the catalysis of reverse hydrolysis using galactosidases $^{23}$. Carbohydrates that cannot be hydrolysed and absorbed during their transit through the human gastrointestinal system but are hydrolysed and metabolised by beneficial bacteria residing in the human colon are considered to be "prebiotics". Both FOS and GOS fall within this definition and HMO behave partially in such a manner since some are also found intact in the faeces of breast-fed infants ${ }^{24}$. Therefore, both FOS and GOS have been studied for their abilities to emulate the physiological and biochemical effects of HMO. Although the rest of the present review is focused on experiences with HMO and breast milk, it is important to refer the reader to experiences with non-human oligosaccharides because, as stated above, formulae supplemented with these structures have already reached the market place.

\section{Human Milk and HMO}

Since several HMO contain blood/tissue specific antigens, and lactating mothers belong to different blood/tissue antigen groups, milk samples are varied in their glycosylation. This is due to the fact that the HMO repertoire in a sample constitutes a phenotype of secondary gene products (oligosaccharides) that result from the expression and activity of primary gene products (the enzymes that synthesise oligosaccharides). Erney et al. and Thurl et al. described HMO profiles that agree with the predicted variability of phenotypes according to the Lewis Blood Group and Secretor status of the donor $^{25,26,27}$. More recently, Chaturvedi et al. ${ }^{28}$ corroborated the findings of Enrney et al. in terms of HMO profile variability amongst samples and through lactation. Enrney and Prieto have assembled evidence of the existence of profiles that are not consistent with predictions based on known genotypes; the existence of these profiles was preliminary published in an abstract ${ }^{29}$. This evidence indicates that milk from different mothers may be qualitatively and quantitatively different in regard to its oligosaccharide content. This may also apply to other glycoconjugates, for example, glycoproteins that are decorated or remodelled by the same glycosyltransferases that synthesise HMO. Samples from Lewis positive mothers contain both the expected oligosaccharides resulting from the fucosyltransferase encoded by the Le gene and glycoproteins that react with monoclonal antibodies against antigens of the Lewis system. Similarly, transgenic animals expressing glycosyltransferases under a lactogenic promoter produce both neooligosaccharides and neoglycoconjugates $^{30,31}$. The unavoidable conclusion is that breast-milk is different from one mother to the other. Some mothers synthesise fucosylated sugars such as Fuc $\alpha 1-2$ Gal $\beta 1-4 G l c$, others do not, and these oligosaccharides can be present at concentrations up to 2 grams per litre according to our studies. If this oligosaccharide or, in general, Fuc $\alpha 1-2$ Gal residues are important, some breast-fed infants are not being exposed to these structures through their mother's milk. With regard to glycosylation, breast-milk is heterogeneous.

\section{Clinical evidence that supports biological roles for HMO}

Table 1 is a summary of selected results from reports that explored the biological roles of HMO. This table includes studies other than clinical experiences because its purpose is to illustrate prevalent research lines. Also, there is a limited amount of clinical studies that specifically shed light on HMO functions in the paediatric nutritional context. When studying the effects of HMO on breast-fed infants, two confounding factors arise: putative biological effects of HMO have also been ascribed to glycoproteins and glycolipids ${ }^{32,33}$ and supra-molecular constituents of milk ${ }^{34,35}$, and glycoconjugates may share structural features with HMO. These two factors make it difficult to ascertain the particular roles of HMO in clinical studies comparing breast-fed versus formula-fed infants and, to our knowledge, only one clinical study with a formula supplemented with a human milk oligosaccharide has been reported in the literature ${ }^{19}$, Additional factors may confound interpretation of experiments aimed at probing the ability of particular oligosaccharides to function as prebiotics; one of these is the characterisation of species and varieties of components of the intestinal flora. A review of pertinent literature shows that increased faecal counts of lactobacillus and bifidobacterium species are considered to be beneficial outcomes of the ingestion of HMO or other oligosaccharides ${ }^{36}$. One publication suggests the importance of a particular species and variety of bifidobacterium and mentions that the oligosaccharide Lacto-N-neotetraose (Gal $\beta 1-4 G l c N A c \beta 1-3$ 
Table 1. Selected studies that support particular roles for HMO

\begin{tabular}{|c|c|c|c|c|c|}
\hline Type of Study & Key study characteristics & HMO tested & Main outcomes examined & Key findings & Ref. \\
\hline In vivo & $\begin{array}{l}\text { Ability of certain HMO to interfere with } \\
\text { colonisation with S. pneumoniae }\end{array}$ & LNnT and sialylated forms & $\begin{array}{l}\text { Lung colonisation of } S \text {, pneumoniae in rab- } \\
\text { bits. Pharyngeal colonisation of } S \text {, } \\
\text { pneumoniae in rats }\end{array}$ & $\begin{array}{l}\text { Decreased bacterial load in lungs (when } \\
\text { administered intratracheally), prevented } \\
\text { bacteraemia }\end{array}$ & 50 \\
\hline In vitro & $\begin{array}{l}\text { Ability of milk fractions (high or low mol- } \\
\text { ecular weight) to inhibit adhesion of } \\
\text { S. pneumoniae and } H \text {. influenzae }\end{array}$ & $\begin{array}{l}\text { A fraction of milk with Lacto- } \\
\text { Neo series HMO }\end{array}$ & $\begin{array}{l}\text { Adhesion of } S \text {. pneumoniae and } \mathrm{H} \text {. } \\
\text { influenzae }\end{array}$ & $\begin{array}{l}\text { The oligosaccharide fraction of milk inhibited } \\
\text { adherence of } S \text {. pneumoniae and the high } \\
\text { molecular weight fraction inhibited } \\
\text { adherence of } \mathrm{H} \text {. influenzae }\end{array}$ & 49 \\
\hline $\begin{array}{l}\text { Clinical } \\
\text { (Cohort) }\end{array}$ & $\begin{array}{l}\text { Diarrhoea in breast-fed infant-mother } \\
\text { pairs }(n=93) \text {; mothers with differing } \\
\text { Lewis blood groups }\end{array}$ & Fuc $\alpha 1-2$ versus other Fuc $\alpha-R$ & Diarrhoea incidence in infants. & $\begin{array}{l}\text { Milk with higher ratio of 2-linked fucosylated } \\
\text { versus non-2-linked oligosaccharides } \\
\text { conferred protection }\end{array}$ & 41 \\
\hline $\begin{array}{l}\text { In vitro and } \\
\text { In vivo }\end{array}$ & $\begin{array}{l}\text { Ability of 2'FL to inhibit adhesion of } \\
\text { Campylobacter jejuni to target cell- } \\
\text { s/tissues }\end{array}$ & 2'FL & $\begin{array}{l}\text { Adhesion of Campylobacter jejuni to cells in } \\
\text { the presence of 2'FL; Ability of milk with } \\
2^{\prime} F L \text { to inhibit colonisation in rat pups }\end{array}$ & $\begin{array}{l}\text { 2' FL inhibits } C \text {. Jejuni adhesion to WHAT??. } \\
\text { Pups fed milk with 2'FL showed reduced } \\
\text { colonisation }\end{array}$ & 40 \\
\hline Clinical & $\begin{array}{l}(n=228) \text { Six-month and older infants; } \\
\text { one group fed supplemented formula }\end{array}$ & LNnT & $\begin{array}{l}\text { Colonisation of throat and nasopharynx with } \\
\text { S. pneumoniae and } H \text { influenzae }\end{array}$ & $\begin{array}{l}\text { Colonisation was not reduced, formula was } \\
\text { well tolerated, trend to reduction of } \\
\text { "inflamed" ears }\end{array}$ & 19 \\
\hline $\begin{array}{l}\text { Analysis of } \\
\text { faeces }\end{array}$ & Presence of oligosaccharides in faeces & Several & Presence of oligosaccharides in faeces & $\begin{array}{l}\text { Apparent different oligosaccharide metabolism } \\
\text { in term versus preterm infants; Presence of } \\
\text { oligosaccharides in faeces suggests they } \\
\text { may act as fibres }\end{array}$ & 44,45 \\
\hline In vitro & In vitro digestibility of $\mathrm{HMO}$ & $\mathrm{HMO}$ in general & HMO digestibility & $\begin{array}{l}\text { Less than } 5 \% \text { of } \mathrm{HMO} \text { are digested by human } \\
\text { enzymes; } \mathrm{HMO} \text { are available to act as } \\
\text { prebiotics in the colon or as fibres }\end{array}$ & 47 \\
\hline $\begin{array}{l}\text { Analysis of } \\
\text { faeces }\end{array}$ & $\begin{array}{l}\text { Determine bifidobacteria and entero- } \\
\text { bacteria }\end{array}$ & Human milk & $\begin{array}{l}\text { Bacterial counts of faeces from breast-fed } \\
\text { and formula-fed infants }\end{array}$ & $\begin{array}{l}\text { Enterobactaria are reduced in breast-fed } \\
\text { infants. Bifidobacteria are dominant }\end{array}$ & 46 \\
\hline
\end{tabular}


Gal $\beta 1-4 G l c)$ is a particularly suitable prebiotic for such a microbe $^{37}$. While this may be true for in vitro experiences there is no clinical evidence to support this assertion. Species and strains are sometimes confused because of the lack of standards to define them. More than ten years ago Dubey and Mistry ${ }^{38}$ reported another confounding factor: species of bifidobacterium grow at different rates under the same conditions. These include degree of anaerobiosis, $\mathrm{pH}$, particular nutrients and temperature. Conducting in vitro studies to determine the prebiotic effect of oligosaccharides is relatively easy and results of significant difference can be detected ${ }^{19}$. This is true when comparing bacterial responses to different oligosaccharides using either growth or selected metabolic or enzymatic activities as benchmarks. In contrast, similar experiences in the presence of relatively large concentrations of lactose (such as in milk) generate results that are difficult to interpret. When saccharide-supplemented infant formula is used to assess its prebiotic effect as a whole, other factors such as the concentration of lactulose (generated during the thermal process) become critical because its prebiotic effect may mask or enhance the effect of other saccharide structures $^{39}$. In lactose-free formulations the concentration of sucrose becomes as important specially when assessing the effects of fructooligosaccharides. As indicated above, only one clinical study has been published in which a pure HMO was used to supplement infant formula. The oligosaccharide $(\mathrm{LNnT})$ was present in formula at the average concentration in which it is found in breast milk $(200 \mathrm{mg} / \mathrm{l})$. Perhaps such a study should only be considered a proof of the concept that demonstrates the feasibility of conducting large-scale clinical studies with HMO-supplemented formulae. A detailed analysis of Table I reveals that a systematic effort has been conducted by Ruiz-Palacios and coworkers to probe the anti-pathogenic effects of fucosylated oligosaccharides, specifically those that contain the Fuc $\alpha 1-2$ structural motif $^{40,41}$. This group used $\mathrm{CHO}$ cells transfected with a human fucosyltransferase that catalyses the synthesis of Fuc $\alpha$ 1-2 residues. These cells express fucosylated glycoproteins in their cell surfaces which allowed them to compare the ability of strains of enteropathogenic Campylobacter jejuni to bind to these cells and to the wild type ${ }^{42}$. In addition they also took advantage of a transgenic animal model in which mice expressing the same fucosyltransferase express $2^{\prime} \mathrm{FL}$ in their milk ${ }^{30}$. The investigators inoculated newborn mouse pups with $C$. jejuni and compared the persistence of colonisation in pups fed by transgenic mothers and those fed by wild type mice. Pups fed with milk containing transgenically expressed Fuc $\alpha 1-2$ oligosaccharides and glycoconjugates shed the pathogenic bacteria faster than pups fed with control milk. Furthermore, this group also conducted a cohort study to determine the effect of Fuc $\alpha 1-2$ on diarrhoea ${ }^{41}$. Because some mothers do not synthesise this structure, they were able to ascertain that infants fed milk containing Fuc $\alpha 1-2$ were less susceptible to diarrhoea. In this particular case there is a clear progression from in vitro to clinical relevance. Other studies have compared the ability of breast-milk to promote colonisation with bifidobacteria or lactobacillus, or to decrease counts of pathogenic bacteria, or have focused on quantifying HMO in faeces ${ }^{43,44,45}$. Ex vivo digestibility studies complement these observations ${ }^{46}$. The evidence suggests that the least controversial role for $\mathrm{HMO}$ is as primordial fibres and prebiotics as elucidated by Coppa and coworkers ${ }^{47}$. Additional work has been conducted to determine if HMO can be used as nutritional anti-infectives ${ }^{48,49}$. In this regard, the work by Idänpään and coworkers was predicated on the ability of a particular structural feature of oligosaccharides to inhibit colonisation of epithelial cells of animals with S. pneumoniae. This work also evolved in demonstrations of efficacy in animal models and progress into the referred clinical trial ${ }^{19}$.

\section{Conclusions}

HMO present unique problems for the assessment of their biological functions and the conducting of tests in the context of paediatric nutrition. The work of Ruiz-Palacios and coworkers suggests that infants fed with milk lacking or having low concentrations of $2^{\prime}$ FL may be more susceptible to diarrhoea than their counterparts fed with human milk containing $2^{\prime} \mathrm{FL}^{40}$. This simple observation implies that emulating human milk and HMO is not as simple as previously thought. HMO may provide nutritional advantages to infants but may also have other applications. If it is true that fucosylated glycoconjugates that contain Fuc $\alpha 1-2$ residues provide protection from diarrhoea in a paediatric nutritional context, then these saccharides could be excellent candidates to develop pharmaceutical applications for adults as well as infants. It is proposed here that it is no longer sufficient to reiterate that "more research is needed in the field of HMO"; now that these structures can be synthesised in large quantities it is feasible to pursue at least two classical paths of inquiry; 1) traditional in vitro, in vivo safety and pharmacokinetic studies ${ }^{50}$ and 2) well-controlled clinical trials. The first approach may or may not lead to nutritional applications but may branch out as a specific type of pharmaceutical pool of drug candidates ${ }^{51}$. Recognition of subtleties and perhaps limitations imposed by nature on breast-milk and its components is the first step to understanding applications of HMO that extend beyond the realm of nutrition.

\section{Conflict of interest statement}

PAP worked for Abbott Laboratories until March, 2007 and still holds stocks of this company in his retirement fund. Abbott Laboratories produces infant formula. RME and MT have no conflict of interest to declare. The article was co-written by all authors.

\section{References}

1. Grimmonprez L \& Nontreuil L (1975) Isolation and physicochemical proprties of oligosaccharides of human milk. $J$ Biochimie 57, 695-671.

2. Urashima T, Kobayashi M, Asakuma S, Uemura Y, et al. (2007) Chemical characterization of the oligosaccharides in Bryde's whale (Balaenoptera edeni) and Sei whale (Balaenoptera borealis lesson) milk. Comp Biochem Phys B 146, 153-159.

3. Uemura Y, Asakumna S, Yon L, et al. (2006) Structural determination of the oligosaccharides in the milk of an Asian elephant (Elephas maximus). Comp Biochem Physiol Part A Mol Integr Physiol 145, 468-478.

4. Lara-Villoslada F, Debras E \& Nieto A (2006) Oligosaccharides isolated from goat milk reduce intestinal inflammation in a rat 
model of dextran sodium sulfate-induced colitis. Clin Nutr $\mathbf{2 5}$, 477-488.

5. Gopal PK \& Gill HS (2000) Oligosaccharides and glycoconjugates in bovine milk and colostrums. Br J Nutr 84, Suppl 1, S69-S74.

6. Urashima T, Messer M \& Bubb WA (1992) Biosynthesis of marsupial milk oligosaccharides II: Characterization of a beta 6-N-acetylglucosaminyltransferase in lactating mammary glands of the tammar wallaby, Macropus eugenii. Biochim Biophys Acta 1117, 223-231.

7. Messer M, Gadiel PA, Ralston GB, et al. (1983) Carbohydrates of the milk of the platypus. Aust J Biol Sci 36, 129-137.

8. Kobata A, Yamashita K \& Tachibana Y (1978) Oligosaccharides from human milk. Meth Enzymol 50, 216-220.

9. Kobata A, Ginsburg V \& Tsuda M (1969) Oligosaccharides of human milk. I. Isolation and characterization. Arch Biochem Biophys 130, 509-513.

10. Kobata A (1970) Human milk oligosaccharides and blood groups-with special reference to the $\mathrm{ABH}$ and Lewis blood groups. Seikagaku 42, 829-841.

11. Prieto P \& Smith D (1984) A new sialyloligosaccharide from human milk: isolation and characterization using anti-oligosaccharide antibodies. Arch Biochem Biophys 229, 650-656.

12. Egge H, Dell A \& Von-Nicolai H (1983) Fucose containing oligosaccharides from human milk. I. Separation and identification of new constituents. Arch Biochem Biophys 224, $235-253$.

13. Zopf D, Smith D, Drzeniek Z, Tsai M, et al. (1978) Affinity purification of antibodies using oligosaccharide-phenethylamine derivaties coupled to Sepharose. Meth Enzymol 50, $171-175$.

14. Smith D, Prieto P \& Torres V (1985) Rabbit antibodies against the human milk sialyloligosaccharide alditol of LS-tetrasaccharide a (NeuAc alpha 2-3Gal beta 1-3GlcNAc beta 1-3Gal beta 1-4GlcOH). Arch Biochem Biophys 241, 298-303.

15. Magnani J, Nilsson B, Brockhaus M, et al. (1982) A monoclonal antibody-defined antigen associated with gastrointestinal cancer is a ganglioside containing sialylated lacto-N-fucopentaose II. J Biol Chem 257, 14365-14369.

16. Prieto P \& Smith D (1985) A New ganglioside from Human meconium detected by Anti-serum against the human milk sialyloligosaccharide L-S-Tetrasaccharide b. Arch Biochem Biophys 241, 281-289.

17. Newburg D (1999) Human milk glycoconjugates that inhibit pathogens. Curr Med Chem 6, 117-127.

18. Hakomori S (2001) Tumor-associated carbohydrate antigens defining tumor malignancy: basis for development of anticancer vaccines. Adv Exp Med Biol 491, 369-402.

19. Prieto $\mathrm{P}$ (2005) In vitro and clinical experiences with a human milk oligosaccharide, Lacto-N-neoTetraose, and Fructooligosaccharides. Foods and Food Ingredients J. Jpn 210, 1018-1030.

20. Su YC, Sheu CS, Chien JY, et al. (1991) Production of betafructofuranosidase with transfructosylating activity for fructooligosaccharides synthesis by Aspergillus japonicus NTU-1249. Proc Natl Sci Counc Repub China B. 15, 131-139.

21. Lopez H, Coudray C \& Levrat-Verny M (2000) Fructooligosaccharides enhance mineral apparent absorption and counteract the deleterious effects of phytic acid on mineral homeostasis in rats. $J$ Nutr Biochem 11, 500-508.

22. Zdunczy Z, Król B, Juskiewicz J, et al. (2005) Biological properties of fructooligosaccharides with different contents of kestose and nystose in rats. Arch Anim Nutr 59, 247-256.

23. Sowimol C, Vasileios I, Keshavan N, et al. (2005) Synthesis of galacto-oligosaccharide from lactose using beta- galactosidase from Kluyveromyces lactis: Studies on batch and continuous
UF membrane-fitted bioreactors. Biotechnol Bioeng 89, 434-443.

24. Sabharwal H, Sjöblad S \& Lundblad A (1991) Sialylated oligosaccharides in human milk and feces of preterm, full-term, and weaning infants. J Pediatr Gastroenterol Nutr 12, 480-484.

25. Erney R, Malon T, Skelding M, et al. (2000) Variability of Human Milk Neutral Oligosaccharides in a Diverse Population". J. Ped Gastroent. Nutr. 30, 181-192.

26. Erney R, Pickering L, Ruiz-Palacios G \& Prieto P (2001) Human Milk Oligosaccharides: A novel Method Provides Insight into Human Genetics. In Advances in Experimental Medicine and Biology, pp. 285-297 [S David, editor]. New York, NY: Kluwer Academic/Pleum Publishers 501.

27. Thurl S, Heneker J, Siege M, Tovar K \& Sawatzki G (1997) Detection of four human milk groups with respect to Lewis Blodd Group Dependent Oligosaccharides. Glycoconj J 14, 795-799.

28. Chaturvedi P, Warren C, Altaye M, et al. (2001) Fucosylated human milk oligosaccharides vary between individuals and over the course of lactation. Glycobiology 11, 365-372.

29. Prieto P, Hilty M, Erney R, Pickering L \& Palacios G (1996) Fucosylated Oligosaccharides of Human Milk: Unusual Profiles, Abstract. Glycobiology 6, 730.

30. Prieto P, Mukerji P, Kelder B, et al. (2005) Remodeling of Mouse Milk Glycoconjugates by Transgenic Expression of a Human Glycosyltransferase. J Biol Chem 270, 2915-2919.

31. Kelder B, Enreny R, Kopchick J, et al. (2001) Glycoconjugates in Human and Transgenic Animal Milk. In Advances in Experimental Medicine and Biology, pp. 269-278 [Newburg David S, editor]. New York, NY: Kluwer Academic/Pleum Publishers 501.

32. Bessler HC, de Oliveira IR \& Giugliano LG (2006) Human milk glycoproteins inhibit the adherence of Salmonella typhimurium to HeLa cells. Microbiol Immunol. 50, 877-882.

33. Rueda R, Sabatel J, Maldonado J, et al. (1998) Addition of gangliosides to an adapted milk formula modifies levels of fecal Escherichia coli in preterm newborn infants. $J$ Pediatr 133, 90-94.

34. Keenan TW (1974) Composition and Synthesis of Gangliosides in Mammary Gland and Milk of the Bovine. Biochim Biophys Acta 337, 255-270.

35. Keenan TW (2001) Assembly and Secretion of the Lipid Globules of Milk. In Bioactive Components of Human Milk, pp. 125-136 [David Newburg, editor]. Advances in Experimental Medicine and Biology. New York, NY, United States: Kluwer Academic/Plenum Publishers Volume 501.

36. Kunz C, Rudloff S Baier W, Klein N, et al. (2000) Annu Rev Nutr 20, 699-672.

37. Kunz C \& Rudloff S (1993) Biological functions of oligosaccharides in human milk. Acta paediatrica 82, 903-912.

38. Dubey K \& Mistry V (1996) Effect of bifidogenic factors on growth characteristics of bifidobacteria in infant formulas. J Dairy Sci 79, 1156-1163.

39. Vanhoutte T, De Preter V, De Brandt E, et al. (2006) Molecular monitoring of the fecal microbiota of healthy human subjects during administration of lactulose and Saccharomyces boulardii. Appl Environ Microb 72, 5990-5997.

40. Ruiz-Palacios GM, Cervantes LE, Ramos P, Chavez-Munguia B \& Newburg DS (2003) Campylobacter jejuni Binds Intestinal $\mathrm{H}(\mathrm{O})$ Antigen (Fucalpha 1, 2Galbeta1, 4GlcNAc), and Fucosyloligosaccharides of Human Milk Inhibit Its Binding and Infection. J. Biol. Chem. 278, 14112-14120.

41. Newburg D, Ruiz-Palacios G, Altaye M, et al. (2004) Human milk alphal,2-linked fucosylated oligosaccharides decrease risk of diarrhea due to stable toxin of E. coli in breastfed infants. Adv Exp Med Biol 554, 457-461. 
42. Prieto PA, Larsen RD, Cho M, Rivera H, et al. (1997) Expression of Human H-Type $\alpha 1$,2-Fucosyltransferase Encoding for Blood Group $\mathrm{H}(\mathrm{O})$ Antigen in chinese hamster ovary cells. J Biol Chem. 272, 2089-2097.

43. Sabharwal H, Nilsson B, Grönberg G, Chester M-A, et al. (1988) Oligosaccharides from feces of preterm infants fed on breast milk. Arch Biochem Biophys 265, 390-406.

44. Sabharwal H, Nilsson B, Chester M-A, Lindh F, et al. (1988) Oligosaccharides from faeces of a blood-group B, breast-fed infant. Carbohydr Res 178, 145-154.

45. Iseki K (1987) Development of intestinal flora in neonates. Hokkaido Igaku Zasshi. 62, 895-906.

46. Gnoth M, Kunz C, Kinne-Saffran E \& Rudloff S (2000) Human Milk Oligosaccharides are minimally digested in vitro. J Nutr 130, 3014-3020.
47. Coppa G, Bruni S, Morelli L, Soldi S \& Orazio G (2004) The first prebiotics in humans: human milk oligosaccharides. J Clin Gastroenterol 38, Suppl., S80-S83.

48. Andersson B, Porras O, Hanson L, Lagergård T \& SvanborgEdén C (1986) Inhibition of attachment of Streptococcus pneumoniae and Haemophilus influenzae by human milk and receptor oligosaccharides. J Infect Dis 153, 232-237.

49. Idänpään-Heikkilä I, Simon P, Zopf D, Vullo T, et al. (1977) Oligosaccharides interfere with the establishment and progression of experimental pneumococcal pneumonia. J Infect Dis 176, 704-712.

50. Leach J, Garber S, Marcon A \& Prieto P (2005) In vitro and in vivo effects of soluble, monovalent globotriose on bacterial attachment and colonization. Antimicrob Agents Chemother 49, 3842-3846.

51. Kobata A (2003) Possible application of milk oligosaccharides for drug development. Chang Gung Med J. 26, 621-636. 